\title{
Special issue on radical views on cognition: introduction
}

\author{
Marcos Silva $^{1}$. Francicleber Ferreira ${ }^{1}$
}

Published online: 3 January 2021

(c) Springer Nature B.V. 2021

Several contemporary philosophers have been articulating tenets in pragmatism (broadly construed) to motivate this view as an alternative philosophical foundation for a comprehensive understanding of cognition, opposed to a far-reaching representationalist tradition. This long-established representationalist tradition in philosophy of mind and cognitive science defends that cognition is fundamentally content-involving. On the other side, some radical contenders advocate that cognition is neither representational nor does it involve, as in usual internalist views, picking up and processing informational contents that are used, stored and reused to get cognitive work done. They call attention to the importance of inherited and embodied practices and social interactions in order to understand relevant topics in the nature of perception, intentionality and language, for instance. Contenders take seriously both evolving biological systems and situated individuals interacting in communities over time as preconditions for our rationality, features often dismissed as not central in the representationalist and internalist tradition.

More recently, some approaches incorporate further biological insights into the discussion of cognition, by calling attention to basic facts about living organisms such as their perpetual activity of self-construction (autopoiesis), their need to be constantly adapting to the changing conditions of the environment (adaptivity), and their selective responsiveness to specific aspects of the environment creating their own world of significance (enaction). Following on this trend, radically enactivist approaches take the bold further step of proposing the complete removal of representational content in the explanation of cognition in basic minds, not only for simple organisms but also at the human level. Moreover, the conservative view that content is the mark of the cognitive should be rejected.

Together with embodied, embedded, and ecological approaches, this radical research program has been successful in providing explanations for a wide variety of basic cognitive phenomena. However, a straight solution to the full naturalization of the concept of content and mental representations requires, among other points, explaining how it is possible to get from informational foundations that are allegedly

Marcos Silva

marcossilvarj@gmail.com

1 Recife, Brazil 
non-contentful to a full theory of mental content using only the resources of an explanatory naturalism.

Furthermore, a more radical approach to cognition faces the so-called "scale-up objection", namely, the challenge of proving itself relevant for the investigation of traditional problems related to higher level cognition involving concepts such as contentful information, representational states, symbolic thought, logic, mathematics etc.

Our special issue is organized around these challenges. We begin with contributions concerning subpersonal cognitive activities as perception and memory, dealing with intentionality and phenomenally, and then turn to the personal and social level where cooperation, language and normativity arise.

In their contribution, Miguel Segundo-Ortin and Daniel D. Hutto explicate how similarity based cognition can be understood through the lens of radical enactivism and why doing so has advantages over its representationalist rival. Erik Myin, in his paper, shows how a correct understanding of the way in which basic and contentless cognition relate allows us to see how REC can accommodate evidence on affordance perception, and thus can afford affordance perception itself. In their paper, Maxwell J. D. Ramstead, Michael D. Kirchhoff, Axel Constant and Karl J. Friston approach the issue of how and where to draw the boundaries of cognitive systems through a multiscale ontology of cognitive systems, which offers a multidisciplinary research heuristic for cognitive science. Mario Villalobos' paper examines a fundamental philosophical difference between autopoietic theory and the enactive approach. The ways these two theories understand cognition, he argues, are neither compatible nor incompatible, but rather incommensurable. Tobias Schlicht's contribution evaluates the advantages of an autopoietic-enactive approach to the naturalization of intentionality and ends with a suggestion how cognition may relate to intentionality and representation. In their paper, Guilherme Sanches de Oliveira, Vicente Raja, Anthony Chemero challenge a persistent criticism of radical embodied cognitive science: it is impossible to explain "real cognition" without invoking mental representations and providing an account of explicit, real-time thinking of the kind we engage in when we imagine counter-factual situations, remember the past, and plan for the future.

Fred Keijzer's contribution introduces the new concept of cobolism as a complement to metabolism. Cobolism, he defends, refers to the systematic ways in which each living system encompasses structures, processes and external events that maintain the fundamental metabolic processes that constitute the core of each living system. In her paper, Alessandra Buccella, using Merleau-Ponty's philosophy, defends that perceptual experience is in an important sense indeterminate and that this is crucial, she argues, if we want to understand perceptual presence and the 'problem' of perceptual presence that Noë solves. Julian Kiverstein and Erik Rietveld also use some points of Merleau-Ponty's philosophy to argue that people can think about absent, abstract or counterfactual state of affairs because of their skills for engaging with what they call "enlanguaged affordances". Thomas van Es' paper draws on the subject of whether perception involves the manipulation of representations. He then defends how the Embedded View championed by, for example, Orlandi should be best altered to be a non-representational theory of perception. Juan Camilo Espejo-Serna's contribution argues that Radical Enactivism should change its view on phenomenality: either deny that the environment plays any role in an account of the phenomenal character or 
embrace the view that the phenomenal properties of experiences are at least partly constituted by the environment itself. In his paper, Eric Epstein draws on Milikan's work and argues that attention to the ways that beliefs' effects on behavior are modulated by background beliefs can help to illuminate the facts that underlie their intentionality and content. Farid Zahnoun's contribution argues that, contrary to popular belief, we don't yet have any compelling reason to assume that nonrepresentationalist theories are, as a matter of necessity, limited in scope. He defends that Clark and Toribio's influential argument in terms of 'representation-hungry' cognition is, for various reasons, flawed. Eros Carvalho, in his paper, defends that an organism learns to perceive an object by becoming sensitized to its affordances. His ecological disjunctivism amounts to that a case of perception and its corresponding case of hallucination are indeed different in nature. Kourken Michaelian's paper claims that radical enactivism aligns neatly with an emerging tendency in the philosophy of memory, namely, radical enactivists and causal and postcausal theorists of memory have begun to converge, for distinct but compatible reasons, on a contentless conception of memory traces.

To begin a discussion on personal and social level in radical views on cognition, Manuel Heras Escribano suggests a promising first step for offering a systematized and consistent post-cognitivist approach to cognition that retains the full potential of both enactivism and ecological psychology. These two different processes of organic coordination, he defends, can be integrated in a post-cognitivist research framework, which will be based on two levels of analysis: the subpersonal one (the neural dynamics of the sensorimotor contingencies and the emergence of enactive agency) and the personal one (the dynamics that emerges from the organism-environment interaction in ecological terms). Concerning mental disorders, Joel Krueger's paper argues that an enactive approach to direct social perception can clarify some ways we play a regulative role in shaping the temporal and phenomenal character of mental disorders, and it may therefore have, he argues, practical significance for both the clinical and therapeutic encounter. Victor loughlin's paper, drawing on some remarks about seeing-as, shows how Wittgenstein poses a challenge for proponents of Sensorimotor Enactivism, like O'Regan and Noë, namely to provide a sensorimotor framework within which seeingas can be explained. He maintains that they should endorse what he calls Sensorimotor Identification, according to which visual experiences can be identified with what agents do. Daniele Moyal-Sharrock, contra Hutto and Myin's REC, argues that contentinvolving practices are themselves simply a further extension of action and do not therefore warrant being called 'different in kind' or 'kinky'. With the help of Ludwig Wittgenstein and John V. Canfield, she challenges the continuity skeptics and also suggests ways in which Enactivism meets the challenge of explaining higher-level cognition.

Simon Høffding and Glenda Satne offer an original 'Arch' to understanding musical performances: an overarching conception of musical interaction as an externalized, cognitive scaffold that encompasses high and low-level cognition, internal and external processes, as well as the shared normative space including the musical materials in which the musicians perform. Their 'Arch' proposes interaction as a multivariate, multimodal, overarching scaffold necessary to explain not only cases of joint performance, but equally of solo improvisation. In her contribution, Laura Alejandra Mojica Lopez suggests that adaptivity is a property of organism-environment interactions over 
a time span that includes both present and past conditions. Ultrafast performances should thus, she defends, no longer be a challenge for the enactive approach, because the constitutive basis of their normativity is spatiotemporally extensive.

Patricia Fonseca Fanaya's demonstrates that Peirce's semiotic pragmatism can be a meaningful methodological path to guide a reconciliation between not only antiCartesianism and representation but also representation and action. Roberta Dreon claims that Dewey's anti substantial, continuistic, and emergentist conception of the mind as a typically human conduct pulls the rug out of the idea of cognition as representation and pushes the current discussion towards a serious reconsideration of representationalist assumptions about conceptuality and language. In her solo contribution, Glenda Satne seeks to complement the enactivist approach by offering an account of basic joint action that involves and brings with it basic forms of mental understanding. Her paper turns to theories of joint action rather than theories of perception to gain insight into the kind of interactions that underpin our understanding of other minds, and in that way, supplements the interactionist-enactive account.

Karim Zahidi's paper critically examines the view that there are fundamental limitations to non-representational explanations of cognition. Rather than challenging these arguments on general grounds, he investigates a set of human cognitive capacities that are generally thought to fall outside the scope of nonrepresentational accounts, namely, numerical cognition. After criticizing standard representational accounts of numerical cognition for their lack of explanatory power, he argues that a non-representational approach that is inspired by radical enactivism offers the best hope for developing a genuine naturalistic explanatory account for these cognitive capacities.

Pierre Steiner, in his contribution, suggests that Larry Laudan's theory of research traditions is more enlightening than Kuhn's theory for describing the scope and ambitions of radical views on cognition, and their relations with an anti-intellectualist tradition in philosophy. There might be good reasons to think, he holds, that cognitive science is in a situation of foundational crisis, but that does not entail that the classical paradigm (computationalism) is currently displaced to the benefit of a new paradigm. Giovanni Rolla develops a Radically Enactive notion of Rationality (RER), according to which rationality is embodied, situated and contentless. For his RER, an organism acts rationally insofar as it sustains a proficient interaction with its environment, which in turn requires the coordination of cognitive abilities in accordance with environmental constraints.

We hope that this Special Issue will foster new agenda and research projects, both radical and non-radical, and shed some light in classical problems in philosophical discussion on cognitive activities.

Publisher's Note Springer Nature remains neutral with regard to jurisdictional claims in published maps and institutional affiliations. 